Application forms for tickets of admission and for copies of papers, and further information about the discussion may be obtained from the Secretary, Institution of Mechanical Engineers, Storey's Gate, St. James's Park, London, S.W.l.

\section{A Naked-eye Group of Sunspots}

A VERY large group of sunspots, that is likely to develop into the largest group so far recorded during the present eleven-year cycle, came into view at the sun's east limb on July 22 in latitude $31^{\circ} \mathrm{N}$. The date of central meridian passage is July $28 \cdot 5$; on August 4, the group will reach the sun's west limb. The group comprises a large leader spot and a follower of composite structure ; these, with companion spots, covered no less than 2,000 millionths of the sun's hemisphere on July 24. On July .26 (the date of this report) the two chief component spots could be distinguished separately with the naked eye.

\section{The Night Sky in August}

THE moon is new on August 6 at $12 \cdot 6^{\mathrm{h}}$ and full on August $22^{\mathrm{h}}$ at $0 \cdot 8^{\mathrm{h}}$. U.T. Conjunction with the planet Venus occurs on August 3 at $9^{\mathrm{h}}$, and from the northern part of England and in Scotland an occultation can be seen (see Nature, July 17, p. 103). On August 18 at $23^{\mathrm{h}}$, there is a conjunction with Jupiter, and on August 24 at $20^{\mathrm{h}}$ a conjunction with Saturn. On August 30, the moon occults the 5th magnitude star, o Tauri, the re-appearance at Greenwich taking place at $3^{\mathrm{h}} 20^{\mathrm{m}}$ at position angle $314^{\circ}$ from the moon's north point. From sunset until sunrise during August, four bright planets are visible. Mars sets before midnight; Jupiter is on the meridian at $2 \frac{3}{4}^{\mathrm{h}}$ in the middle of the month, followed by Saturn at $2 \frac{3}{4}^{\mathrm{h}}$; whilst Venus rises at about $1 \frac{1}{4}^{\mathrm{h}}$ and is a brilliant object in the early morning skies, passing between Procyon and Castor and Pollux towards the end of the month. Uranus is nearly stationary in Aries and may be picked out from the background of stars of similar magnitude (about $6^{\mathrm{m}}$ ) with the help of the map given on p. 57 of the B.A.A. Handbook. At about $21^{\mathrm{h}}$ the constellations on the meridian offer almost unlimited scope for interesting 'sweeps', which should include double stars such as $\alpha$ Herculis, $\theta$ Serpentis, $\beta$ Cygni, $\gamma$ Delphini and $\delta$ Cephei. The latter star is a notable short-period variable giving its name to a class of variable which, recognizable in the nearer extra-galactic nebulæ, enables the distances of these remote systems to be determined. Of the nebulæ and star clusters to be viewed with binoculars or a small telescope, the 'ring' nebula in Lyra, the 'dumb-bell' nebula in Vulpecula and the star cluster in Hercules should be easily located by means of a star atlas. The general outline of the Milky Way may also be studied with binoculars, noting the bifurcation near the bright star, Deneb, and the star clouds near the southern horizon. It may be recalled that towards a point at R.A. $18^{\mathrm{h}} 4^{\mathrm{m}}$ : Dec. $+31^{\circ}$ the solar system is moving into space with a speed of 12 miles a second. Between August 10 and 12, in particular, the sky may be watched for meteors of the Perseid stream. An ephemeris for the comet
Grigg-Skjellerup is given on p. 32 of the B.A.A. Handbook and also one for the comet Encke, which may possibly be picked up before long on its return to perihelion due next December. The periodicity of this comet, only $3 \cdot 3$ years-the shortest known period for a comet-was first recognized by Encke in 1819 .

\section{Announcements}

The Earl of Rothes has accepted the appointment of chairman of the governors of Faraday House Electrical Engineering College, in succession to the late Lord Castletown.

Dr. L. J. Spencer, formerly keeper of minerals in the British Museum, has been elected a corresponding member of the Société Géologique de Belgique.

Prof. L. J. WitTs, professor of medicine in the University of London and physician to St. Bartholomew's Hospital and Prof. G: E. Gask, emeritus professor of surgery in the University of London, have been appointed members of the Medical Research Council, in succession to Sir Thomas Lewis and Sir David P. D. Wilkie, who retire on September 30 .

THE Trustees have appointed Dr. S. Ochoa of the University of Madrid as Ray Lankester investigator for 1937, and Dr. Ochoa began his researches at the Marine Biological Association's laboratory in Ply. mouth on July 1, his subject being the experimental relationship of structure to environment in fishes and other animals. This work is a continuation of previous researches at Madrid and Heidelberg on the same subject.

The first International Congress of Medical Public Health Officers organized by the syndicate of French medical hygienists under the auspices of the Health Section of the League of Nations will be held in Paris on October 20-21 under the presidency of Prof. J. Pariset. Further information can be obtained from Voyages Duchemin-Exprinter, 26 Avenue de l'Opéra, Paris le.

The twenty ninth Annual Autumn Meeting of the Institute of Metals will be held at Sheffield on September 6-9. On September 6, Dr. D. R. Pye, deputy director of scientific research, Air Ministry, will deliver the sixteenth Autumn Lecture entitled, "Metallurgy and the Aero Engine". Further information can be obtained from the Secretary, Institute of Metals, 36 Victoria Street, London, S.W.1.

THE fourteenth annual conference of the Association of Special Libraries and Information Bureaux (ASLIB) will be held at Gonville and Caius College, Cambridge, on September 24-27, under the presidency of Sir Harry Lindsay, director of the Imperial Institute, who will give an address on "The Inter. relation between Science, Agriculture and Industry". Further information can be obtained from the General Secretary, ASLIB, 31, Museum Street, London, W.C.1. 